\title{
A Large Polypoid Vascular Ectasia Removed by Using a Polypectomy With a Detachable Snare in an Asymptomatic Patient
}

\author{
Byung Hyun Yu, Sung Jae Shin, Kwang Wook Lee, Kyoung Ho Ryoo, Jeong Ook Wi, Joon Hwan Yoo, \\ Jeong Woo Choi \\ Department of Gastroenterology, Ajou University School of Medicine, Suwon, Korea
}

\begin{abstract}
Vascular ectasia is a well-known cause of lower gastrointestinal bleeding in the elderly. Endoscopically, it usually appears as a flat or elevated bright red lesion. We report on an extremely rare case of a large, pedunculated, polypoid vascular ectasia in an asymptomatic patient. A large pedunculated polypoid mass in the sigmoid colon was observed on colonoscopy during a regular health check-up, and a polypectomy was performed using a detachable snare. In histology, vessels with massive dilation were found mainly in the submucosa, which was consistent with vascular ectasia.
\end{abstract}

Keywords: Pedunculated polyp; Vascular ectasia; Detachable snare

\section{INTRODUCTION}

Vascular ectasias are the most common vascular lesions observed in the gastrointestinal tract and probably the most frequent cause of recurrent or chronic lower intestinal bleeding in persons over the age of 60. Colonic vascular ectasias are also known as arteriovenous malformations (AVMs) or angiodysplasia, meaning that the condition involves abnormal dilation of a blood vessel, which is thought to be caused by degenerative changes [1]. These lesions may be solitary or multiple, isolated abnormalities, or part of a systemic disorder [2].

Vascular ectasias have mainly been discovered in the appendix and the ascending colon, and approximately $10 \%$ are found in the distal small bowel. Endoscopically, vascular ectasias generally appear as flat or slightly elevated bright red lesions [3]. A peduncu-

Received: April 13, 2012 - Accepted: August 27, 2012

Correspondence to: Sung-Jae Shin, Ph.D.

Department of Gastroenterology, Ajou University School of Medicine,

206 World cup-ro, Yeongtong-gu, Suwon 443-721, Korea

Tel: +82-31-219-6939, Fax: +82-31-219-5999

E-mail: shsj9128@ajou.ac.kr

(C) 2013 The Korean Society of Coloproctology

This is an open-access article distributed under the terms of the Creative Commons Attribution NonCommercial License (http://creativecommons.org/licenses/by-nc/3.0) which permits unrestricted noncommercial use, distribution, and reproduction in any medium, provided the original work is properly cited. lated appearance is extremely rare [3]. We report on a large, pedunculated, polypoid, vascular ectasia, which was successfully removed by using an endoscopic polypectomy with a detachable snare.

\section{CASE REPORT}

A 50-year-old man was referred to Ajou University Hospital for a large pedunculated polyp, which was found on colonoscopy during a regular health check-up. The patient had no symptoms and no history of gastrointestinal bleeding, such as melena or hematochezia. In the laboratory findings, hemoglobin was $15.3 \mathrm{~g} / \mathrm{dL}$, and hematocrit was $43.7 \%$.

At the time of colonoscopy, a pedunculated polypoid mass measuring approximately $4 \mathrm{~cm}$, with a long stalk, was found in the sigmoid colon (Fig. 1). The head portion of the polyp had a hyperemic mucosal surface with some folds, but no evidence of hemorrhage. To prevent bleeding during polypectomy, we applied a detachable snare to the base of the mass, and we performed a polypectomy successfully without complications (Fig. 2). Pathologic results showed an edematous submucosa with an obvious dilated vein lined with endothelial cells, which was consistent with a vascular ectasia (Fig. 3). 


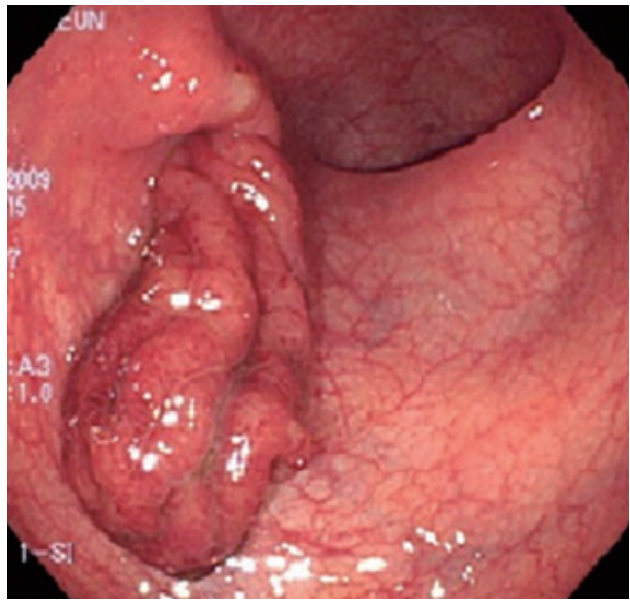

Fig. 1. A large pedunculated polypoid lesion (Ip type) was seen in the colonoscopy. The mucosa was hyperemic, and the surface had some folds.

\section{DISCUSSION}

Vascular ectasia of the colon was first found during intraoperative angiography by Margulis et al. [4] in 1960 and was diagnosed using colonoscopy by Skibba et al. [5] in 1976. The incidence of vascular ectasia detected by colonoscopy has been reported to range from $1 \%$ to $6 \%[6,7]$. Regarding the pathogenesis of vascular ectasia, intermittent low-grade obstruction of submucosal veins was thought to have an important role, involving penetration of muscular layers of the colon, causing small AVMs [1]. This resulted in increased pressure in the venules and capillaries, causing vascular dilatation, tortuosity, and arteriovenous shunts. Histologically, hypertrophy of the submucosal layer, infiltration of inflammatory cells, and irregularly-thickened vessels were found [8].

A pedunculated, polypoid-shaped, colonic vascular ectasia has been reported in 9 cases, including our case. The sizes of the pedunculated vascular ectasias ranged from 0.7 to $6.2 \mathrm{~cm}$, and their main symptom was gastrointestinal bleeding. Hematochezia developed in seven of the 9 cases, iron deficiency anemia in one, and no symptoms in our case. As to shape, seven were pedunculated polyps, and two were semipedunculated polyps. Most of the cases were initially mistaken for a polyp. All things considered, an elevated bright red lesion with a fern-like pattern or ectatic blood vessels radiating from a central vessel must be considered as a vascular ectasia, not a polyp.

As to treatment, six of the 9 cases were treated by using a snare polypectomy or an endoscopic mucosal resection whereas one was treated with a bowel resection, owing to its large size [8], and of the snare polyectomy cases, one required epinephrine and argon plasma coagulation, owing to excessive bleeding [9]. In the remaining 2 cases, including our case, an endoscopic removal with a detachable snare and a polypectomy was done, but having such a patient without symptoms was a first. Therefore, if a polyp is sus-
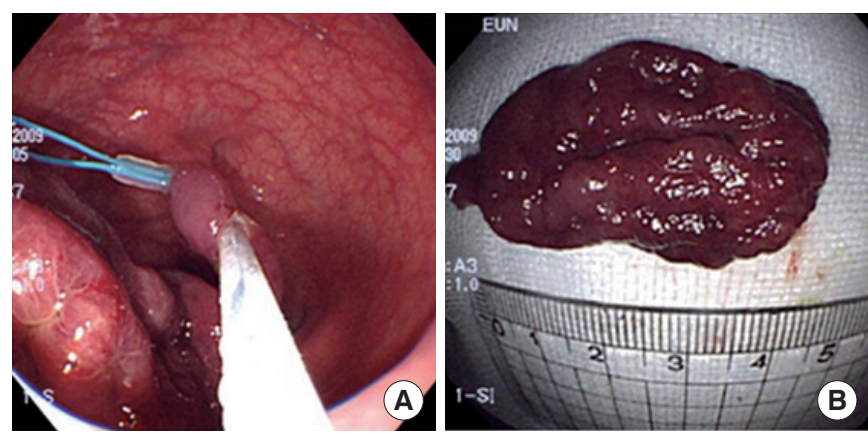

Fig. 2. A snare polypectomy was performed after the stalk of the polyp had been tied by using a detachable snare (A). The specimen measured approximately $4.6 \mathrm{~cm} \times 2.0 \mathrm{~cm}$ (B).
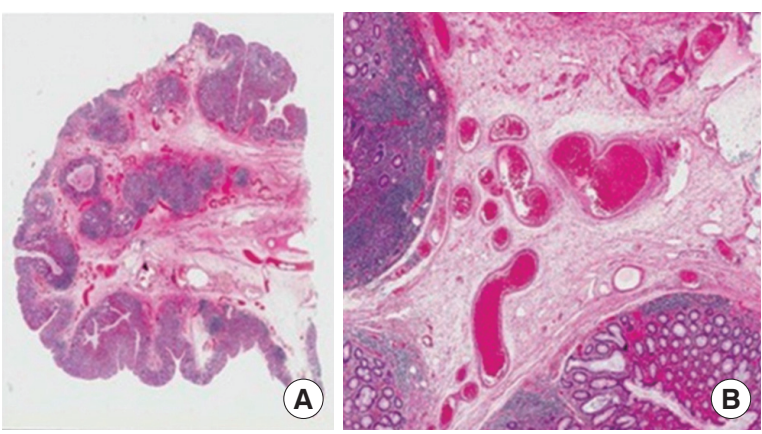

Fig. 3. Histopathologic findings of the polyp shows irregular dilatation of venous structures in the edematous submucosal space (H\&E: $\mathrm{A}, \times 10 ; \mathrm{B}, \times 40)$.

pected to be hypervascular or to have a high bleeding risk, as in this case, injection of a sclerosing agent or use of a detachable snare prior to a polypectomy may prevent bleeding after the polypectomy [10].

In summary, we reported on a large pedunculated polyp, which was confirmed as an vascular ectasia after a polypectomy, in an asymptomatic patient.

\section{CONFLICT OF INTEREST}

No potential conflict of interest relevant to this article was reported.

\section{REFERENCES}

1. Boley SJ, Sammartano R, Adams A, DiBiase A, Kleinhaus S, Sprayregen S. On the nature and etiology of vascular ectasias of the colon: degenerative lesions of aging. Gastroenterology 1977; 72(4 Pt 1):650-60.

2. Greenwald DA, Brandt LJ. Vascular abnormalities of the gastrointestinal tract. In: Feldman M, Scharschmidt BF, Sleisenger MH, editors. Sleisenger \& Fordtran's gastrointestinal and liver disease: pathophysiology, diagnosis, management. 6th ed. Philadelphia: 
Saunders Co.; 1998. p. 2024-34.

3. Koziara FJ, Brodmerkel GJ, Boylan JJ, Ciambotti GF, Agrawal RM. Bleeding from polypoid colonic arteriovenous malformations. Am J Gastroenterol 1996;91:584-6.

4. Margulis AR, Heinbecker P, Bernard HR. Operative mesenteric arteriography in the search for the site of bleeding in unexplained gastrointestinal hemorrhage: a preliminary report. Surgery 1960; 48:534-9.

5. Skibba RM, Hartong WA, Mantz FA, Hinthorn DR, Rhodes JB. Angiodysplasia of the cecum: colonoscopic diagnosis. Gastrointest Endosc 1976;22:177-9.

6. Heer M, Sulser H, Hany A. Angiodysplasia of the colon: an expression of occlusive vascular disease. Hepatogastroenterology 1987;
34:127-31.

7. Moore JD, Thompson NW, Appelman HD, Foley D. Arteriovenous malformations of the gastrointestinal tract. Arch Surg 1976;111: 381-9.

8. Maeng L, Choi KY, Lee A, Kang CS, Kim KM. Polypoid arteriovenous malformation of colon mimicking inflammatory fibroid polyp. J Gastroenterol 2004;39:575-8.

9. Nasseri-Moghaddam S, Mohamadnejad M, Malekzadeh R, Tavangar SM. Images of interest. Gastrointestinal: polypoid arteriovenous malformation of the colon. J Gastroenterol Hepatol 2004; 19:1419.

10. Hachisu T. A new detachable snare for hemostasis in the removal of large polyps or other elevated lesions. Surg Endosc 1991;5:70-4. 